\title{
Endometritis tuberculosa sin foco primario y dolor pélvico crónico
}

\author{
Beatriz Navarro Santana ${ }^{1}$, Raquel Sanz Baro ${ }^{1}$, Franklin Idrovo ${ }^{2}$, Javier Plaza Arranz ${ }^{1}$, \\ Manuel Albi. ${ }^{1}$ \\ ${ }^{1}$ Departamento de Ginecología y Obstetricia, ${ }^{2}$ Departamento de Anatomía Patológica, Hospital Fundación Jiménez \\ Díaz. Madrid, España.
}

\section{RESUMEN}

Antecedentes: La tuberculosis genital y la endometritis tuberculosa es una forma de tuberculosis que continúa siendo frecuente en los países en desarrollo y habitualmente es secundaria a un foco primario pulmonar. Puede cursar de forma asintomática, o bien, producir síntomas como infertilidad primaria o secundaria, alteraciones menstruales o dolor pélvico crónico, entre otros. Caso clínico: Se presenta el caso de una paciente de 47 años en estudio por ginecología y urología por dolor pélvico crónico y sintomatología urinaria inespecífica de aproximadamente 6 meses de evolución. La ecografía transvaginal muestra contenido intracavitario escaso sugerente de piometra e imágenes trabeculares compatibles con sinequias uterinas. Mediante aspirado endometrial se extrae pus y muestra endometrial que se remite para estudio anatomopatológico. Tras el informe anatomopatológico que diagnostica inflamación crónica granulomatosa necrotizante, se solicita estudio por PCR y cultivo para micobacteriumm tuberculosis, siendo ambos positivos para el microorganismo. De este modo, se diagnosticó como endometritis tuberculosa sin existir afectación de otros órganos tras el estudio completo. Se realizó tratamiento con etambutol hidrocloruro, isoniacida, pirazinamida y rifampicina durante 2 meses y pirazinamida e isonicida durante 7 meses adicionales. Al final del tratamiento, la paciente mostraba clara mejoría de los síntomas y a la ecografía desaparición de la colección intracavitaria uterina.

\section{PALABRAS CLAVE: Tuberculosis, endometritis tuberculosa, tuberculosis genital femenina}

\section{SUMMARY}

Background: Genital tuberculosis and endometritis tuberculosa is a form of tuberculosis which remains prevalent in developing countries and is usually secondary to a pulmonary primary focus. It may be asymptomatic, or may produce symptoms such as primary or secondary infertility, menstrual disorders or chronic pelvic pain, among others. Clinical case: We present the case of a patient of 47 -year who was studied by ginecology and urology for chronic pelvic pain and unspecific urinary symptoms since about 6 months. In transvaginal ultrasound pyometra and trabecular images compatible with uterine synechiae were observed. Endometrial samples were obtaining and sent for histopathologic examination which was informed of chronic necrotizing granulomatous inflammation. We asked for PCR and culture for tuberculosis micobacteriumm, both being positive for the microorganism. Thus, she was diagnosed of endometritis tuberculosa without involvement of other organs after complete study. She performed a treatment with ethambutol hydrochloride, isoniazid, rifampicin and pyrazinamide for 2 months and pyrazinamide and isoniazid for 7 months. At the end of treatment, the patient showed clear improvement of symptoms and disappearance of uterine intracavitary collection in the ultrasonographic study.

KEY WORDS: Tuberculosis, endometritis tuberculosa, female genital tuberculosis 


\section{INTRODUCCIÓN}

La tuberculosis genital en mujeres no es infrecuente, sobre todo en comunidades donde la tuberculosis pulmonar u otras formas de tuberculosis genital son frecuentes. La tuberculosis puede afectar a cualquier parte del cuerpo y puede cursar de forma asintomática y/o recurrente. Desde la década de los años veinte la tuberculosis ha disminuido en los países desarrollados, pero ha aumentado en los países en desarrollo (1). La prevalencia más alta se encuentra en las mujeres en edad fértil, donde tiene el mayor impacto en su fertilidad (2).

En el tracto genital femenino el sitio más frecuentemente afectado son las trompas de Falopio, seguida del endometrio. Las manifestaciones clínicas más comunes incluyen disfunciones menstruales (amenorrea, metrorragia), infertilidad primaria o secundaria, dolor abdominal bajo, dolor pélvico crónico. El estandar para el diagnóstico es el cultivo de micobacterias (1).

Se presenta el caso de una paciente que acudió a nuestro departamento con dolor pélvico crónico y que fue diagnosticada de endometritis tuberculosa y que tras tratamiento médico su patología fue completamente resuelta.

\section{Caso clínico}

Se presenta el caso de una mujer, de origen peruano, de 47 años con antecedente de una gastropatía ulcerosa y pólipos hiperplásicos de antro gástrico y alergia documentada al metamizol. Como antecedentes gineco-obstétricos había presentado un parto eutócico y un aborto tardío de 20 semanas que requirió legrado evacuador obstétrico por persistencia de restos placentarios. Posteriormente, menstruaciones regulares hasta los 41 años, edad a la que refiere su última menstruación. A los 45 años, refiere episodio de sangrado y hematómetra que precisó legrado en su país de origen, del que no aportaba informes ni estudio histológico. No había presentado ningún otro episodio de sangrado. La paciente aportaba un cribado citológico negativo adecuado.

Desde hacía más de seis meses, la paciente refería dolor pélvico y sintomatología urinaria inespecífica sin respuesta a analgesia habitual. La paciente se había realizado repetidos urocultivos negativos para infección durante ese periodo. En la exploración física, se objetivó un abdomen blando y depresible, doloroso a la palpación en hipogastrio y exploración ginecológica sin hallazgos significativos. En la ecografía ginecológica se objetivaron anexos normales y un pio/hidrometra de $12 \times 14 \mathrm{~mm}$ con trabeculaciones avasculares sugestivas de sinequias (Figura 1). Se realizó evacuación de contenido purulento de la cavidad mediante aspirado con cánula de Cournier con obtención de muestras para estudio microbiológico e histológico. El primer cultivo microbiológico identificó flora mixta vaginal y la histología informó de inflamación crónica granulomatosa necrotizante (Figura 2). Por este motivo, se obtuvo una nueva muestra para cultivo específico y detección por PCR de Micobacterium tuberculosis. La detección por PCR fue positiva y la paciente fue remitida a la unidad de enfermedades infecciosas para estudio y tratamiento. A las tres semanas, el resultado del cultivo también demostró crecimiento del microorganismo.

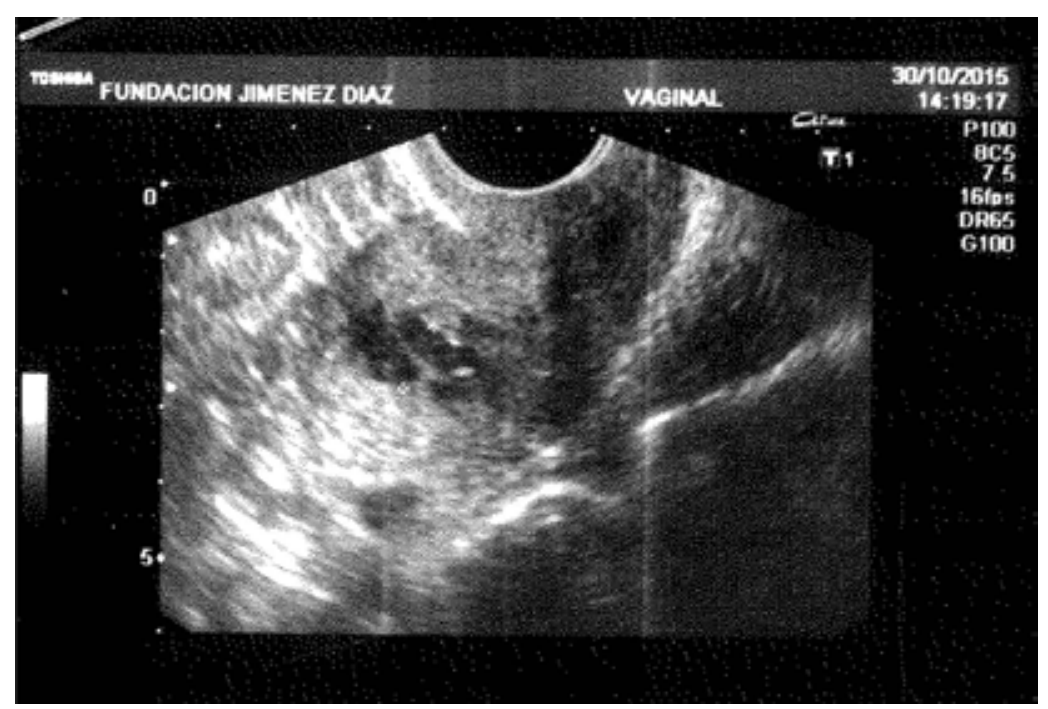

Figura 1. Ecografía transvaginal: Se aprecia un pio/hidrometra de $12 \times 14 \mathrm{~mm}$ con trabeculaciones avasculares sugestivas de sinequias. 


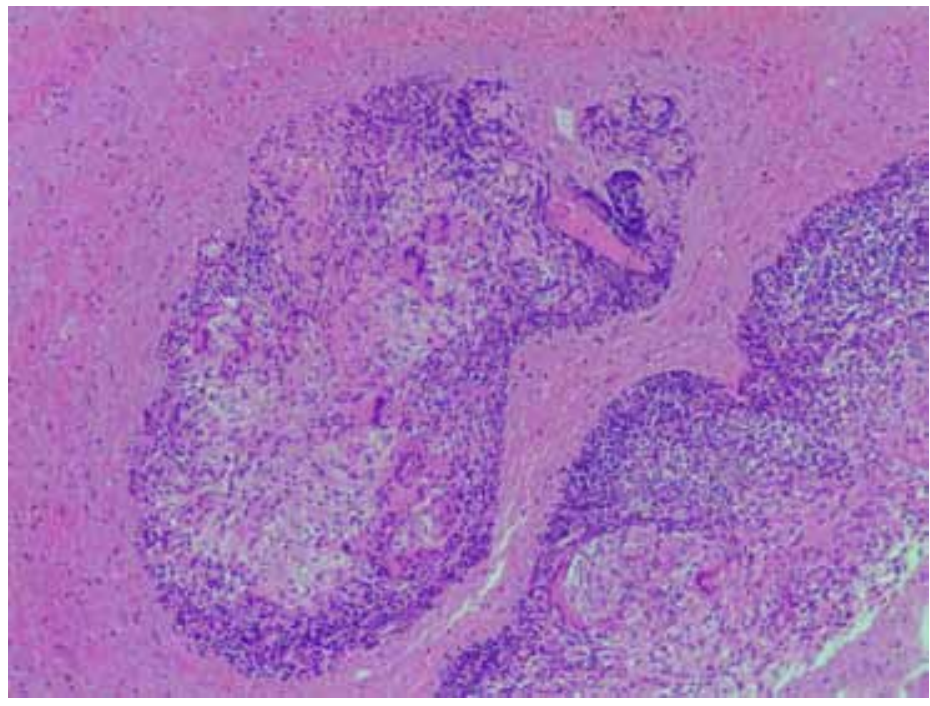

Figura 2. Biopsia endometrio: granulomas epitelioides con presencia de necrosis de tipo caseoso y células gigantes multinucleadas de tipo Langhans. (HE 200x).

Se realizaron radiografía de tórax y analítica con hemograma bioquímica y $\mathrm{Ca} 125$ que fueron normales. No se recogió muestra de esputo pues la paciente no era capaz de expectorar, sin embargo, no presentaba sintomatología respiratoria.

Se decidió iniciar tratamiento con RIMSTAR® (150 mg de rifampicina, $75 \mathrm{mg}$ de isoniazida, $400 \mathrm{mg}$ de pirazinamida y $275 \mathrm{mg}$ de hidrocloruro de etambutol) cuatro comprimidos al día durante dos meses y posteriormente RIFINAH® (300 mg de rifampicina y $150 \mathrm{mg}$ de isoniazida) dos comprimidos al día durante 7 meses. Durante el tratamiento, la paciente comenzó a referir epigastralgia y pirosis, por lo que se decidió realizar una gastroscopia con toma de biopsia que fue informada como negativa para Micobacterium tuberculosis. Finalizado el tratamiento, se objetivó una ecografía vaginal normal (Figura 3) y la mejoría del dolor pélvico de la paciente.

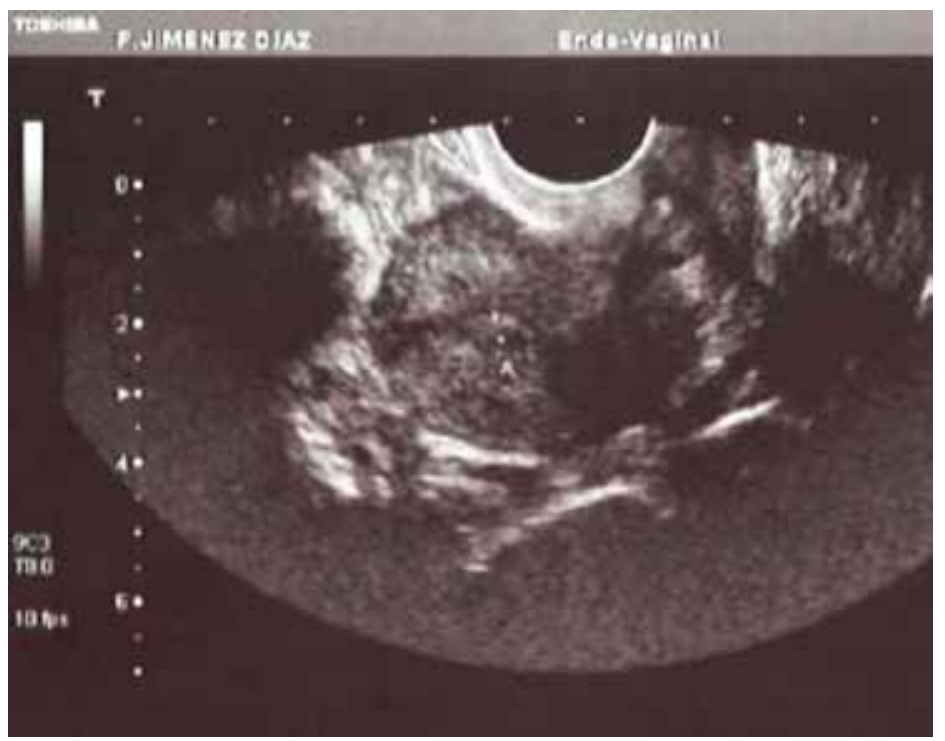

Figura 3. Ecografía transvaginal: se aprecia una resolución del pio/hidrometra previo tras tratamiento médico. Endometrio de 3,3 $\mathrm{mm}$. 


\section{DISCUSIÓN}

La tuberculosis genital es una causa de infertilidad femenina, alcanzando una prevalencia de $1 \%$ en los países desarrollados (ejemplo EEUU) y de $19 \%$ en los países en desarrollo (ejemplo India), siendo este país el con mayor número de casos (1). La prevalencia más alta se encuentra en las mujeres en edad fértil, donde tiene el mayor impacto en su fertilidad (2).

La infección en el tracto genital se presenta principalmente como afectación secundaria a una tuberculosis en otro lugar del cuerpo: pulmonar (la más frecuente), renal, gastrointestinal, ósea y ocasionalmente puede ser parte de una tuberculosis miliar. Si los bacilos no son erradicados hay un alto riesgo de reactivación, especialmente si concurren en el mismo paciente la toma de fármacos o la presencia de enfermedades que provocan la atenuación de la respuesta de los linfocitos T (enfermedad de Hodgkin, VIH, esteroides, estrés o malnutrición). El modo de diseminación usualmente es hematógena o linfática y ocasionalmente ocurre por contigüidad desde un foco abdominal o peritoneal $(1,3)$.

El sitio más frecuentemente afectado son las trompas de Falopio (90-100\%), seguida del endometrio (50-60\%), los ovarios (20-30\%), el cérvix (5$15 \%)$ y la vagina y vulva (1\%) (4). Éstas últimas son extremadamente raras y lo más probable es que la infección provenga del tracto genital superior, aunque, más raramente, puede provenir de la pareja sexual si ésta presenta las vesículas seminales o el epidídimo infectados (1). Lo más frecuente, por tanto, es que el sitio inicial de infección sean las trompas de Falopio y que la afectación sea bilateral y que ésta se disemine al útero y al ovario por extensión directa (1).

Las manifestaciones clínicas más comunes incluyen disfunciones menstruales (amenorrea, metrorragia), infertilidad primaria o secundaria, dolor abdominal bajo, dolor pélvico crónico y masa pélvica con o sin síntomas constitucionales como pérdida de peso, fatiga y febrícula. No obstante, a veces es asintomática y se encuentra de manera casual durante el estudio de infertilidad $(4,5)$. En ocasiones, se puede asociar al síndrome de FitzHugh Curtis (6).

En el caso de nuestra paciente, la afectación endometrial aislada fue única y demostrada en los estudios diagnósticos. Su único síntoma era el dolor pélvico crónico probablemente relacionado con la presencia de piometra, en ausencia de clara secreción purulenta, fiebre ni alteraciones analíticas sugestivas de infección. El dolor pélvico como síntoma aislado se presenta frecuentemente varios meses antes de que la paciente consulte al ginecólogo y suele ser leve, pero cuando la enfermedad progresa suele ser más severo y es agravado por el coito y el ejercicio físico (1).
El estándar para el diagnóstico es el cultivo de micobacterias (siendo el medio de LowensteinJensen el más popular), pero las tasas de cultivo positivo en las diferentes muestras del tracto genital son bajas y, además, resulta un desafío debido al largo periodo de cultivo que se requiere $(1,7)$. Dado que la tuberculosis genital es secundaria a una infección primaria del pulmón, parece que una radiografía de tórax podría ser útil en el diagnósti$\mathrm{co}$, aunque sólo se han encontrado anormalidades en el $10-50 \%$ de los casos (1).

En los últimos años, la reacción en cadena de la polimerasa (PCR) para la detección del DNA de las micobacterias ha adquirido una gran sensibilidad y especificidad en el diagnóstico de la tuberculosis abdominal y genital (8). Se han descrito hallazgos laparoscópicos o laparotómicos que podrían corresponder con tuberculosis genital como son las adhesiones pélvicas, hidrosalpinx, piosalpinx, cromoperturbación negativa, adhesiones perihepáticas, masas tuboováricas, ascitis y nódulos granulomatosos (9). La histerosalpingografía y la ecografía tienen baja sensibilidad y baja especificidad para el diagnóstico de tuberculosis genital (7).

La tuberculosis genital puede presentar hallazgos radiológicos diferentes en función de si se trata de un proceso agudo o crónico y del órgano al que afecta (3). De hecho, la histerosalpingografía y la ultrasonografía son las pruebas de imágenes usadas para su diagnóstico $(3,10)$.

Con respecto a la endometritis tuberculosa, como ocurre en el caso de nuestra paciente, el miometrio raramente se presenta afectado por lo que la forma y el tamaño uterino raramente están alterados en las pruebas de imagen (1). La endometritis aguda se puede identificar en la histerosalpingografía como una irregularidad del contorno endometrial. Un signo indirecto de endometritis es la extravasión del contraste en el sistema vascular y linfático. En la ecografía, el endometrio puede estar engrosado e hipoecoico. La endometritis crónica se caracteriza por cicatrización, fibrosis y calcificación. En la ecografía se apreciaría con una apariencia heterogénea del endometrio con áreas hiperecoicas que representan focos de calcificación o de fibrosis, que en última instancia darían lugar a sinequias uterinas y a una cavidad uterina distorsionada: útero pseudounicornuado, útero en T, "collar-stud abscess" y el síndrome de Netter $(3,11)$. La asociación de sinequias extensas con infertilidad se conoce como síndrome de Ashermann (12). En el caso de nuestra paciente, se desconoce si la afectación endometrial podría ser el origen del cese precoz de sus menstruaciones (41 años), así como una posible infertilidad, dado que la paciente no tenía deseo gestacional.

El diagnóstico diferencial de la tuberculosis se debe hacer con otras lesiones granulomatosas como la sarcoidosis, la enfermedad de Crohn, 
actinomiosis, granuloma inguinal, linfogranuloma venéreo, sífilis, histoplasmosis, brucelosis, silicosis, hepatitis, colecistitis, apendicitis, enfermedad renal y cardiaca (1). También puede simular carcinomatosis peritoneal por cáncer de ovario: los hallazgos de masa pélvica, ascitis y Ca 125 elevado se han descrito como presentaciones de tuberculosis genital (13).

Para el tratamiento de la tuberculosis genital se emplean los mismos regímenes de tratamiento que para la tuberculosis pulmonar (1):

a. Un régimen de 6 a 9 meses consistente en isoniacida, rifampicina y pirazinamida durante dos meses seguido de isoniacida y rifampicina durante 4 a 6 meses. Etambutol o estreptomicina deben ser incluidos en el régimen inicial hasta que se conozcan los resultados de sensibilidad de los fármacos, aunque haya poca posibilidad de resistencias.

b. Un segundo régimen de nueve meses de isoniacida y rifampicina en pacientes que no pueden tolerar pirazinamida. Igualmente, etambutol o estreptomicina deben ser incluidos en el régimen inicial hasta que se conozcan los resultados de sensibilidad de los fármacos.

Como complicaciones de la tuberculosis genital se han descrito infertilidad o esterilidad que suele persistir a pesar del tratamiento, embarazo ectópico por el daño tubárico y tuberculosis congénita (1).

\section{CONCLUSIÓN}

La tuberculosis genital se está convirtiendo en una fuente de morbilidad ginecológica en el mundo debido al aumento de los viajes a áreas endémicas, la inmigración desde países con mayor prevalencia, la coinfección con el virus de la inmunodeficiencia humana y a la resistencia de los fármacos contra la tuberculosis. Por ello, que el ginecólogo debe estar preparado para reconocer una tuberculosis pélvica y dar un correcto y temprano tratamiento.

\section{REFERENCIAS}

1. Thankam R, Varma MD. Tuberculosis of the female genital tract. Global Library of Women's Medicine. Disponible en: https://www.glowm.com/section_view/ heading/Tuberculosis $\% 20$ of $\% 20$ the $\% 20$ Female $\% 20$ Genital\%20Tract/item/34\#20681. Acceso marzo de 2014.
2. Qureshi RN, Sammad S, Hamd R, Lakha SF. Female genital tuberculosis revisited. J Pak Med Assoc 2001;51:16-8.

3. Shah HU, Sannananja B, Baheti AD, Udare AS, Badhe PV. Hysterosalpingography and ultrasonography findings of female genital tuberculosis. Diagn Interv Radiol 2015;21:10-5.

4. Schaefer G. Female genital tuberculosis. Clin Obstet Gynecol 1976;19:223-39.

5. Singh N, Sumana G, Mittal S. Genital tuberculosis: a leading cause for infertility in women seeking assisted conception in North India. Arch Gynecol Obstet 2008;278:325-7.

6. Sharma JB, Ray KK, Gupta N, Jain SK, Malhotra N, Mittal S. High prevalence of 5-Fitz-Hugh-Curtis syndrome in genital tuberculosis. Int J GynaecolObstet 2007; 99:62-3.

7. Jindal UN. An algorithmic approach to female genital tuberculosis causing infertility. Int $\mathrm{J}$ Tuberc Lung Dis 2006;10:1045-50.

8. Bhanu NV, Singh UB, Chakraborty M, et al. Improved diagnostic value of PCR in the diagnosis of female genital tuberculosis leading to infertility. J Med Microbiol 2005;54: 927-31.

9. Sharma JB, Roy KK, Pushpraj M, Kumar S, Malhotra $\mathrm{N}$, Mittal S. Laparoscopic findings in female genital tuberculosis. Arch Gynecol Obstet 2008;278:359-64.

10. Farrokh D, Layegh P, Afzalaghaee M, Mohammadi M, Fallah Rastegar Y. Hysterosalpingographic findings in women with genital tuberculosis. Iran J Reprod Med 2015;13:297-304.

11. Ahmadi F, Zafrani F, Shahrzad GH. Hysterosalpingographic appearances of female genital tract tuberculosis: Part II: Uterus. Int Fertil Steril 2014;8:13-20.

12. Ahmadi F, Siahbazi S, Akhbari F, Eslami B, Voshough A. Hysterosalpingography finding in intra uterine adhesion (Asherman's Syndrome): a pictorial essay. Int J Fertil Steril 2013;7:155-60.

13. Adali E, Dulger C, Kolusari A, KurdogluM, Yildizhan R. Pelvic-peritoneal tuberculosis simulating peritoneal carcinomatosis: high clinical suspicion and a minimally invasive procedure. Arch Gynecol Obstet 2009;280:867-8. 